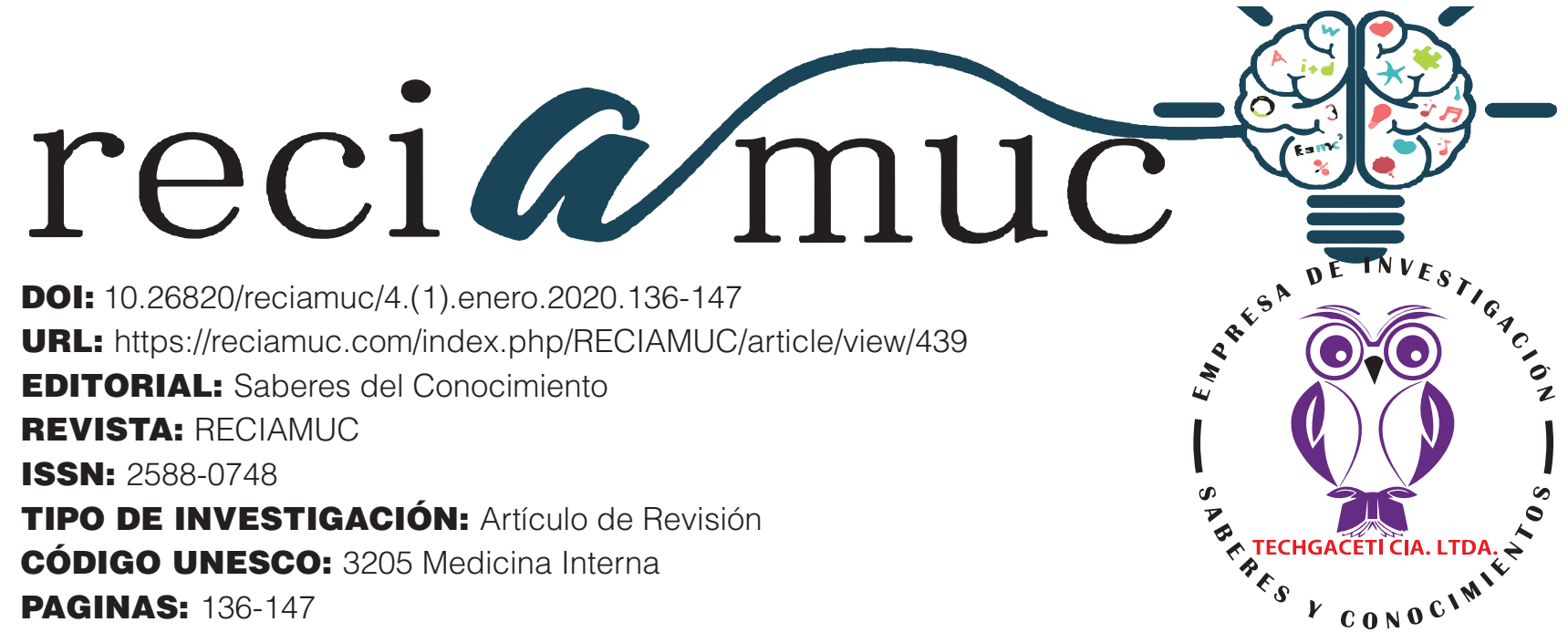

\title{
Regeneración de la pulpa dental con DPSC. Una revisión de la literatura
}

\author{
Regeneration of dental pulp with DPSC. \\ A review of the literature \\ Regeneração de polpa dentária com DPSC. \\ Uma revisão da literatura
}

\begin{abstract}
Fanny Alicia Mendoza Rodríguez'; Jacobo César Rosero Mendoza²; Julio Ildefonso Rosero Mendoza ${ }^{3}$
\end{abstract}

\section{RECIBIDO: 18/11/2019 ACEPTADO: 20/12/2019 PUBLICADO: 31/01/2020}

1. Magister en Diseño Curricular; Doctora en Odontología; Universidad de Guayaquil; Guayaquil, Ecuador; fanny. mendozar@ug.edu.ec; (D) https://orcid.org/0000-0002-5791-5872

2. Especialista en Rehabilitación Oral; Odontólogo; Universidad de Guayaquil; Guayaquil, Ecuador; Jacobo.roserom@ug.edu.ec; (iD https://orcid.org/0000-0002-4162-8385

3. Especialista en Ortodoncia; Magister en Gerencia Hospitalaria; Odontólogo; Universidad de Guayaquil; Guayaquil, Ecuador; julio.roserom@ug.edu.ec; (D) https://orcid.org/0000-0001-5326-3320

CORRESPONDENCIA

Fanny Alicia Mendoza Rodríguez

melissa_carvajalp@hotmail.com

Guayaquil, Ecuador

○ RECIAMUC; Editorial Saberes del Conocimiento, 2019 


\section{RESUMEN}

Son casi 200 tipos de células las que constituyen el cuerpo humano, y estas a su vez se desarrollan a partir de células madre capaces de convertirse en cualquier tipo de tejido del organismo. Actualmente, la regeneración endodóntica representa una de las alternativas y avances más interesantes en el área de endodoncia. La investigación dental aplica protocolos de ingeniería de tejidos y explora el potencial de los productos basados en células como terapias alternativas para reemplazar tejidos como pulpa, dentina y hueso. Los procedimientos de endodoncia regenerativa intentan aplicar procedimientos biológicos para sustituir el tejido complejo de dentina-pulpa perdido / dañado para restaurar la función biológica. El objetivo que se adelantó en este trabajo investigativo, bajo una metodología de revisión, ha sido precisamente referir algunas fuentes bibliográficas que coadyuven en la comprensión de la regeneración de la pulpa dental mediante el uso de DPSC. Con los resultados obtenidos se logró verificar que la literatura cientificoacadémica disponible completa y libremente facilitó la referenciación descriptiva de concepciones fundamentales en cuanto a las células madre de la pulpa dental, la regeneración endodóntica, la regeneración pulpar desde un punto de vista biológico, la regeneración de tejidos con tejido dental derivado de células madre, y la regeneración de tejidos mediante el uso de células madre/progenitoras derivadas de pulpa dental. Se concluye la ingeniería de tejidos recientemente se ha centrado en el avance en cuanto a la regeneración de la pulpa dental, siendo una de sus prioridades el desarrollo de estudios con células madre (in vivo e in vitro), en estos casos usando mayormente las DPSC. Así mismo, que las técnicas más recientes, basadas en el reclutamiento de células progenitoras y la estimulación posterior, siguen prometiendo un inmenso potencial para impactar significativamente en el tratamiento de enfermedades dentales y la promoción de la terapia vital de la pulpa.

Palabras clave: Endodoncia, Ingeniería de Tejidos, Endodoncia Regenerativa, Células Progenitoras, Terapia Endodóncica Basada en Células Madre.

\section{ABSTRACT}

There are almost 200 types of cells that constitute the human body, and these in turn develop from stem cells capable of becoming any type of body tissue. Currently, endodontic regeneration represents one of the most interesting alternatives and advances in the area of endodontics. Dental research applies tissue engineering protocols and explores the potential of cell-based products as alternative therapies to replace tissues such as pulp, dentin and bone. Regenerative endodontics procedures attempt to apply biological procedures to replace the lost / damaged dentin-pulp complex tissue to restore biological function. The objective that was advanced in this research work, under a review methodology, has been precisely to refer to some bibliographical sources that contribute to the understanding of the regeneration of the dental pulp through the use of DPSC. With the results obtained, it was possible to verify that the available and fully available scientific and scientific literature facilitated the descriptive referencing of fundamental concepts regarding the dental pulp stem cells, endodontic regeneration, pulp regeneration from a biological point of view, the regeneration of tissues with dental tissue derived from stem cells, and tissue regeneration through the use of stem / progenitor cells derived from dental pulp. It is concluded that tissue engineering has recently focused on the progress in the regeneration of dental pulp, being one of its priorities the development of studies with stem cells (in vivo and in vitro), in these cases using mostly DPSC . Likewise, that the most recent techniques, based on progenitor cell recruitment and subsequent stimulation, continue to promise immense potential to significantly impact the treatment of dental diseases and the promotion of vital pulp therapy.

Keywords: Endodontics, Tissue Engineering, Regenerative Endodontics, Progenitor Cells, Endodontic Therapy Based on Stem Cells.

\section{RESUMO}

Existem quase 200 tipos de células que constituem o corpo humano, que, por sua vez, se desenvolvem a partir de células-tronco capazes de se transformar em qualquer tipo de tecido corporal. Atualmente, a regeneração endodôntica representa uma das alternativas e avanços mais interessantes na área de endodontia. A pesquisa odontológica aplica protocolos de engenharia de tecidos e explora o potencial de produtos baseados em células como terapias alternativas para substituir tecidos como polpa, dentina e osso. Os procedimentos de endodontia regenerativa tentam aplicar procedimentos biológicos para substituir o tecido do complexo dentina-polpa perdido / danificado para restaurar a função biológica. O objetivo avançado neste trabalho de pesquisa, sob uma metodologia de revisão, foi justamente referir-se a algumas fontes bibliográficas que contribuem para o entendimento da regeneração da polpa dentária através do uso de DPSC. Com os resultados obtidos, foi possível verificar que a literatura científica e científica disponível e totalmente disponível facilitou o referencial descritivo de conceitos fundamentais sobre células-tronco da polpa dentária, regeneração endodôntica, regeneração da polpa do ponto de vista biológico, regeneração de tecidos com tecido dental derivado de células-tronco e regeneração tecidual através do uso de células-tronco / progenitoras derivadas de polpa dentária. Conclui-se que a engenharia de tecidos focou recentemente o progresso na regeneração da polpa dentária, sendo uma de suas prioridades o desenvolvimento de estudos com células-tronco (in vivo e in vitro), nestes casos utilizando principalmente DPSC. Da mesma forma, que as técnicas mais recentes, baseadas no recrutamento de células progenitoras e subsequente estímulo, continuam prometendo imenso potencial para impactar significativamente o tratamento de doenças dentárias e a promoção da terapia pulpar vital.

Palavras-chave: Endodontia, Engenharia de Tecidos, Endodontia Regenerativa, Células Progenitoras, Terapia Endodôntica Baseada em Células-Tronco. 


\section{Introducción}

Es bien sabido que dentro de la boca proliferan muchísimas bacterias. A partir de allí mismo, Mendiburu, Arce, Medina, \& Carrillo (2016) afirman que éstas pueden ser partícipes en el origen de nosologías sistémicas, ya que cualquier lesión en la pulpa dental derivará en el proceso inflamatorio de la misma, y eventualmente, de no ser oportunamente abordada, en una necrosis pulpar. Entonces, estar al tanto y dilucidar la forma en que se generan estos procesos, se convierte en algo trascendental para el odontólogo.

Los medios a través de los cuales esta infección puede llegar hasta la pulpa dental suelen ser a través de la corona (caries, fisuras, fracturas y defectos del desarrollo dentario) o de la raíz del diente (caries del cuello, bolsas periodontales y bacteremias). El 70 al $95 \%$ de las infecciones odontogénicas contienen una flora mixta (aerobia-anaerobia) producidas por unas 5 a 8 especies diferentes entre las que prevalecen cocos Gram positivos aeróbicos (Streptococcus en un 95\%, Staphylococcus en 5\%), cocos Gram negativos anaeróbicos (Peptococcus, Peptostreptococcus spp y Peptostreptococcus micros) y bacilos Gram negativos anaeróbicos (Bacteroides forsythus, Prevotella intermedia, Porphyromonas gingivalis y Fusobacterium spp) (Mendiburu, Arce, Medina, \& Carrillo, 2016, pág. 23)

La terapia de reemplazo es el concepto que se ha venido utilizando últimamente en la odontología contemporánea, en donde se elimina completamente el tejido inflamado o infectado y se sustituye por un material inerte que le permita al diente afectado recuperar algunas de sus funciones como la estética, masticación, fonación y deglución; pero no considera otras propiedades que eran desempeñadas por el órgano perdido como son: la sensibilidad, defensa, regeneración, mantención de la vitalidad y la homeostasis. Debido a esto, los esfuerzos de la investigación se han volcado hacia la búsqueda de una alternativa que pueda cubrir estos requerimientos, y al momento se ha encontrado la mejor opción en la ingeniería de tejidos, con el objetivo de regenerar las estructuras perdidas basándose en su tríada: células madre, andamios y moléculas de señalización. (Astudillo, 2018, pág. 350)

En base al criterio del mismo autor, quien, por cierto, en el área odontológica define a la ingeniería de tejidos como la terapia endodóncica basada en células madre, dice que la misma se encuentra descrita por un enfoque experimental, pero al mismo tiempo, la investigación esencial respecto a las células madres pulpares se encuentra documentada considerablemente, no obstante, aún no se materializa el relación entre los esos dos procesos investigativos: la experimentación fase I y la terapia clínica.

De la misma manera es válido reconocer previos aportes como los de Ishida, Oshima, \& Tsuji (2013) quienes en su momento afirmaban:

Los recientes avances en el desarrollo de la terapia regenerativa han sido influenciados por una gran cantidad de investigaciones previas en desarrollo embrionario, biología de células madre e ingeniería de tejidos. Un atractivo concepto de terapia regenerativa es el trasplante de células madre en varios tejidos y órganos para restaurar la pérdida parcial de la función del órgano y para reparar tejidos, por ejemplo, el uso de células madre neurales en casos de Enfermedad de Parkinson, células madre mesenquimales en casos de infarto de miocardio, células madre hepáticas en casos de insuficiencia hepática, entre otros. El objetivo de la terapia regenerativa es desarrollar órganos de bioingeniería completamente funcionales que puedan reemplazar a los órganos que se han perdido o dañado por lesiones o envejecimiento. En odontología, las células madre del tejido dental y la red de citoquinas que regula el desarrollo de los dientes ha sido bien caracterizada y probablemen- 
te se puede aplicar en el futuro en la reparación de la pulpa dental y tejidos periodontales. (pág. 30)

El objetivo establecido para esta investigación ha sido el de describir aproximadamente lo relacionado a la regeneración de la pulpa dental con DPSC, por ello, la estructura que a continuación se presenta corresponde con acepciones fundamentales en base a criterios de entendidos en el tema, así como también la concepción relativa a las células madre de la pulpa dental, la regeneración endodóntica, la regeneración pulpar desde un punto de vista biológico, la regeneración de tejidos con tejido dental derivado de células madre, y finalmente, la regeneración de tejidos mediante el uso de células madre/progenitoras derivadas de pulpa dental.

\section{Materiales y Métodos}

El objeto de la presente investigación se ha delimitado a la revisión de la literatura cientificoacadémica disponible en diferentes bases de datos consultadas, entre estas: SciELO, Redib, Fundación de Ginebra para la Educación e Investigación Médica (GFMER), PubMed, Mediagraphic, y otras; por ello, disponer de computadoras personales con conexión a internet resultó ser el recurso material por excelencia e indispensable para el desarrollo del presente documento.

La metodología antes mencionada se llevó a cabo los primeros de enero del año en curso, y se incluyeron búsquedas en portales web de varias asociaciones y fundaciones nacionales, regionales e internacionales, que primordialmente pudieran leerse en español e inglés, y preferiblemente, enfocadas en el área de la salud y medicina, y más específicamente en las de odontología y endodoncia. En todas las búsquedas, las expresiones utilizadas fueron: regeneración de la pulpa dental, regeneración tisular y células madre de la pulpa dental (DPSC). Otros criterios de preselección considerados fueron los de idioma (español e inglés) y rango de fechas de publicaciones la cual fue limitada a los últimos diez años.

Todo el contenido analizado corresponde a artículos científicos de cualquier clase (con y sin metadatos) encontrados en revistas de categoría científica, así como también otros tipos de materiales bibliográficos producidos o promovidos por entes, instituciones, organizaciones, sociedades o asociaciones de carácter público o privado, sean nacionales, internacionales o multilaterales; de procedencia Americana o Europea, e inclusive, de cualquier otra región de habla hispana o anglosajona, preferiblemente; que proveyeran de manera completa y gratuita el acceso a libros digitalizados o electrónicos, recursos en formato electrónico o digital de cualquier tipo, archivos o contenidos alusivos a protocolos, consensos, manuales, guías clínicas, boletines informativos, ensayos, tesis de grado, posgrado o doctorado, informes, proyectos y demás documentos.

Seguidamente, entre los propios integrantes de este equipo se comparte y distribuye el compendio del material bibliográfico preseleccionado, para seguidamente llevar a cabo la lectura exhaustiva de cada uno de ellos, a fines de discutirlos.

Cabe destacar que, fue inevitable proceder a depurar los resultados obtenidos, por lo que, de manera progresiva, se fueron aplicando otros criterios de selección tales como: acceso completo y gratuito, idioma español e inglés, área de odontología, endodoncia, salud dental-bucal, medicina, seres humanos; entre otras discreciones inherentes a la especificidad del tema en cuestión. De allí es que, mediante un consensuado discernimiento, se conserva todo el contenido considerado útil para el desarrollo de la presente investigación, y también, se excluye todo el que, por el contrario, no contribuye al objetivo previamente planteado. Así mismo, se desestimaron cartas editoriales, anotaciones académicas y otros tipos de materiales bibliográficos de escaso valor cientificoacadémico o de bajo 
nivel de evidencia.

\section{Resultados}

Cerca de 200 tipos de células son las que componen el cuerpo humano, mismas que se desarrollan a partir de células madre, que particularmente cuentan con la capacidad de convertirse en cualquier tipo de tejido del organismo. Además, se caracterizan por cuatro propiedades generales, a saber: ...no son especializadas, tienen un alto potencial de autorrenovación (dividirse continuamente y dar lugar a células progenitoras), presentan gran proliferación y diferenciación, dando lugar a células especializadas. Existen dos tipos de células madre según su origen: embrionarias y postnatales (adultas); dependiendo la fase en la que se encuentran se diferencian en totipotenciales, pluripotenciales y multipotenciales. Las células embrionarias son producidas a partir de la fecundación, son consideradas totipotenciales porque originan un embrión. Al formarse el blastocisto se identifican células pluripotenciales, diferenciándose en las tres líneas germinales (endodermo, mesodermo y ectodermo). Las células adultas son multipotenciales, encontrándose entre las células de un órgano y su rol principal es reparar y mantener los tejidos del área. Están presentes en médula ósea, tejido graso, músculos, sangre y órganos dentarios. Las células madre derivadas de los dientes destacan por su elevado potencial de multidiferenciación y la capacidad de diferenciarse en tejidos osteo/odontogénicos, adipogénicos y neurogénicos. Estas células residen en nichos específicos en el complejo dental, como: DPSCs (células troncales de la pulpa dental), SHED (células troncales de dientes temporales recientemente exfoliados), PDLSCs (células troncales del ligamento periodontal), ABSCs (células troncales de la papila dental), SCAP (células troncales de la papila apical) y PAFSCs (células troncales del folículo periapical) (Guadarrama, Guadarrama, \& Robles, 2018)
En lo sucesivo, la referencia al acrónimo DPSC es válido para definir "Dental Pulp Stem Cells" que en español equivale a "Células Madre de la Pulpa Dental".

En cuanto a las aplicaciones clínicas odontológicas, estos mismos han referido en base a sus fuentes que, es de dientes permanentes, supernumerarios y ectópicos de donde se obtienen las DPSCs. Así mismo, aseguran que la evidencia resultante de estudios in vivo, ha demostrado que estas poseen una mayor capacidad odontogénica, alto potencial angiogénico, neurogénico y osteogénico en comparación con las células de la médula ósea, y paralelamente, tambien ha sido posible vrificar que estas maduran en diferentes grados, demostrando una jerarquía progenitora; es po ello que, en la reparación de tejidos, algunas células son más eficientes que otras.

Por otra parte, según Munévar (2017), la investigación con células troncales embrionarias ha originado un debtae que, a su vez, ha aperturado un abanico de muchas posibilidades respecto al potencial clínico con las aplicaciones terapéuticas de las terapias basadas en células para enfermedades que abarcan desde el cáncer, el Mal de Alzheimer, las patologías cardiacas, cirrosis hepática y diabetes; criterio con en el que coinciden Ishida et al. (2013), referidos en la introducción de la presente revisión.

Aunque el futuro de la investigación con células troncales es bastante prometedor, la bioingeniería tisular basada en la tecnología con células troncales embrionarias hasta el momento, pese a recientes avances, todavía se encuentra en una etapa temprana de desarrollo. (párr. 1) 


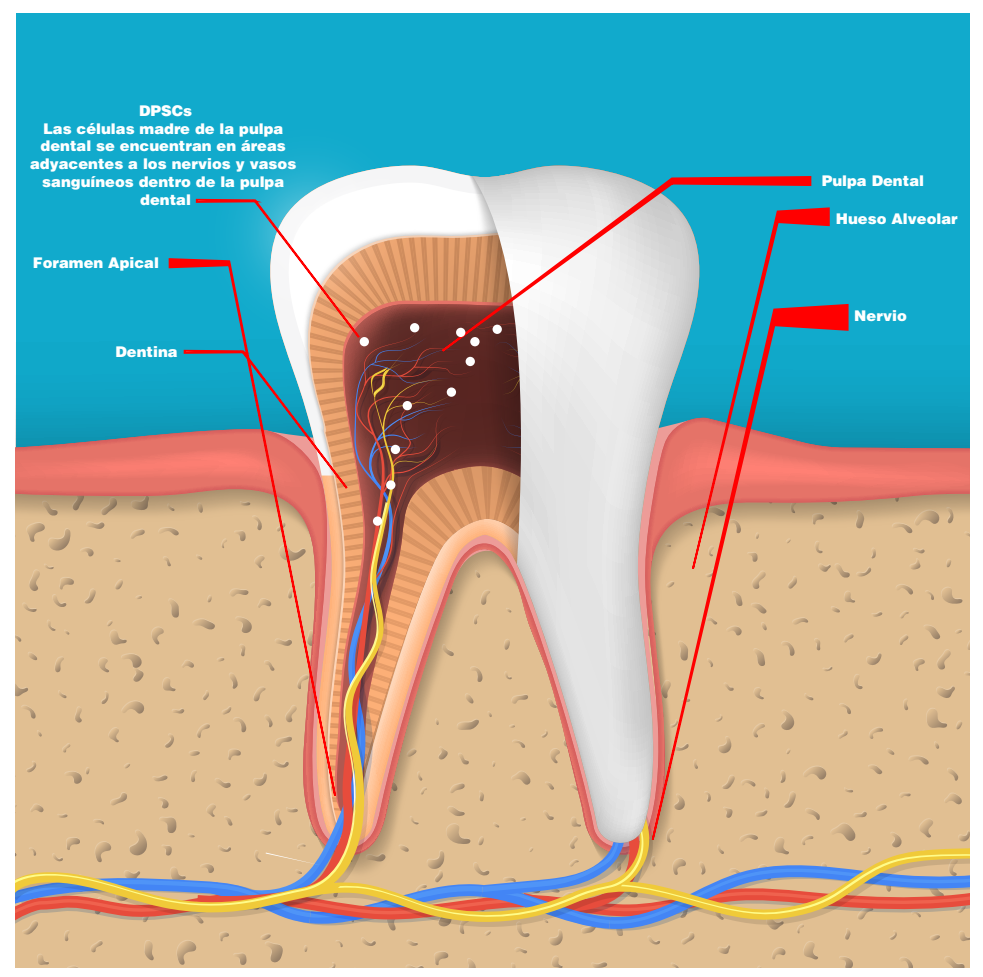

Figura 1. Origen de Células Troncales de Pulpa Dental Humana

Fuente: Autores 2020

\section{Células madre de la pulpa dental}

Las células DPSC, se encuentran en la cavidad interna de las piezas dentales; la cámara central de la cavidad dentaria se compone de un tejido suave infiltrado por una red de vasos sanguíneos y las ramificaciones nerviosas que emanan de la formación apical de la pieza dental. Este tejido suave se conoce como pulpa dental y se compone principalmente por células mesénquimales indiferenciadas (células madre multipotenciales), su morfología es fibroblastoide [ver Figura 2] y se caracterizan por ser células adherentes en cultivo. El tejido pulpar dental puede ser recuperado de las piezas dentales que son extraídas por procedimientos odontológicos de rutina y por previa recomendación médica, ya sea por razones de salud o estéticas, esto puede proceder a lo largo de la vida del individuo, al obtener cultivos de DPSC pueden crio preservarse, garantizando un recurso terapéutico a futuro. $[\ldots]$

La función biológica de las células madre que se encuentran en la cámara pulpar consiste en la reparación de la dentina y el esmalte. (Villa, Flores, \& Santibáñez, 2017, págs. 169-170) 


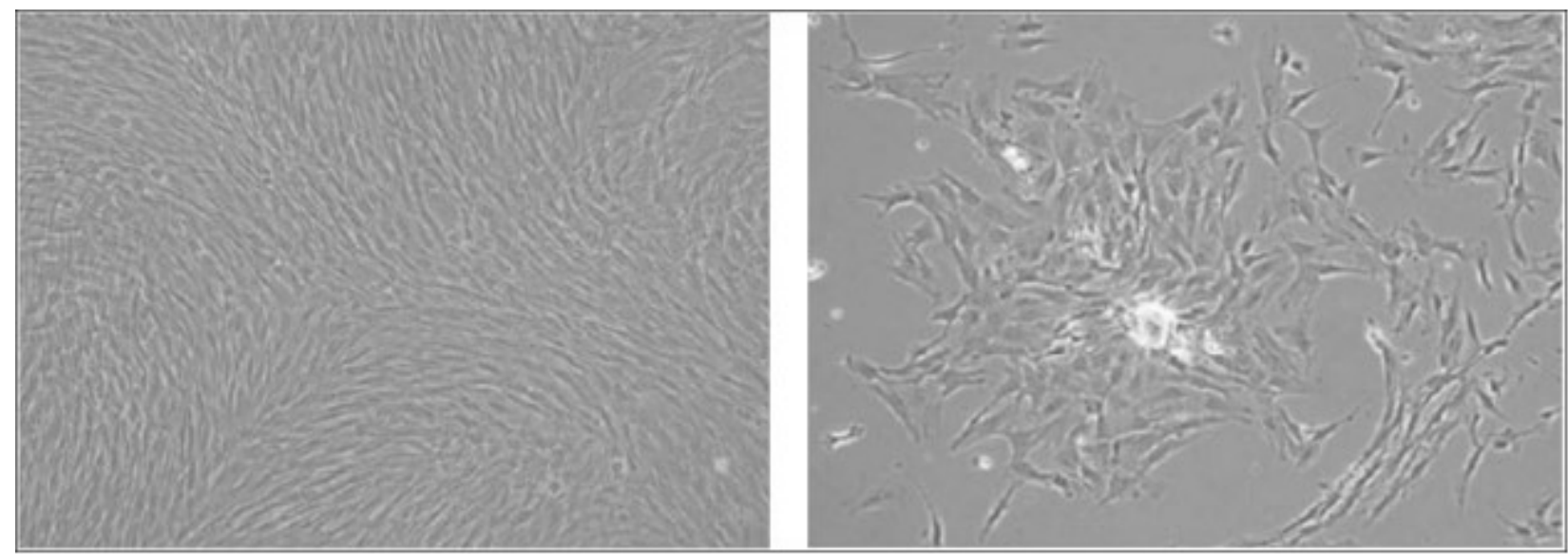

Figura 2. DPSC en cultivo in vitro aisladas de órganos dentarios

Fuente: (Gioventù, Andriolo, Bonino, \& Frasca, 212)

Nota: En la imagen del lado izquierdo se evidencia su morfología fibroblástoide típica, mientras que en la del lado derecho se detalla la formación de colonias circulares.

\section{Regeneración Endodóntica (RE)}

Fernández (2019) ha desarrollado un reciente trabajo investigativo en el que, respecto a este tema, ha expresado que:

Actualmente la RE es una alternativa y uno de los desarrollos más emocionantes en el área de endodoncia. A fin de solventar las principales desventajas de la terapia convencional.

Los principios de la medicina regenerativa se pueden aplicar a la endodoncia con base en la ingeniería tisular. Entendiendo por la misma como un procedimiento cuyo objetivo es regenerar una pulpa funcional que genere nueva demanda dentinária y que sea capaz de responder a un estímulo nocivo.

En otras palabras, la regeneración endodóntica utiliza el concepto de ingeniería tisular para restaurar los conductos radiculares a un estado saludable, lo que permite el desarrollo radicular continuo y del tejido circundante.

En este procedimiento se logra reemplazar la pulpa necrótica con andamios y factores de crecimiento que favorecen la curación, y terapias celulares con el objeto de regene- rar nueva pulpa y dentina dentro del sistema de conductos radiculares. (pág. 20-21)

Esta misma autora, reconociendo la importancia de la triada: células madres, moléculas de señalización (o factores de crecimiento) y soporte físico (o andamio) en el que puede apoyarse el crecimiento y diferenciación celular; en los diversos procesos restaurativos propios de la bioingeniería tisular, ha diferenciado lo siguiente:

Las células madre indiferenciadas cumplen un rol fundamental en la regeneración de los tejidos y en la capacidad de autoreparación del organismo, ya que permiten conformar estructuras biológicas complejas muy alejadas de las generadas por el clínico; como es el caso de tejidos duros presentes en el muñón pulpar y los tejidos periapicales. Adicionalmente, la definen como una célula mesenquimática multipotente de origen postnatal, con propiedades paracrinas, capaz de dividirse continuamente y producir una progenie celular que puede diferenciarse en diversos tipos de células y tejidos, constituyendo lo que se conoce como diferenciación multilinaje.

En ese mismo orden de ideas, las células madre en un principio están indiferencia- 
das, manteniendo su fenotipo hasta que son expuestas a una señal apropiada que estimula la diferenciación y de esta forma generan su función específica.

Dentro de estas células se ubican las de la pulpa dental (DPSC), la de los dientes primarios exfoliados (SHED), de la papila apical (SCAP), del ligamento periodontal (PDLSC), las del folículo de la pulpa dental (DFSC), la de las glándulas salivales (SGSCs), las del epitelio oral (OESCs), las mesenquimales derivadas de la encía (GMSCs), las del germen dentario (TGPCs), las de la médula ósea (BMSC), las derivadas del periostio (PSCs) y las hematopoyéticas (HSCs). (Fernández, 2019, pág. 23) [Ver figura 3]

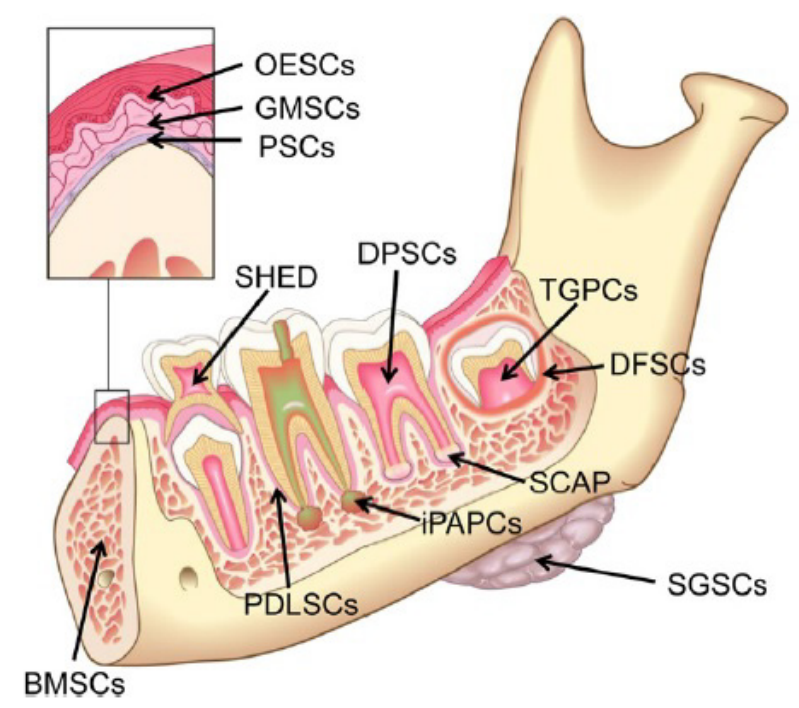

Figura 3. Posibles fuentes de células madre postnatales en la cavidad oral

Fuente: Aguiar, I. (2015)

La regeneración Pulpar desde un punto de vista biológico

Retana (2018) en base a sus fuentes, explica esta perspectiva iniciando con el antecedente de que, uno de los problemas más comunes, nefastos y costosos que se presenta en los servicios de salud humana, son los relacionados con la recuperación de un órgano dañado o tejido perdido.

En relación a ello, continúa explicando la experta que "la ingeniería es una ciencia interdisciplinaria emergente que aplica los principios de biología e ingeniería en medicina regenerativa para mejorar o reemplazar la función biológica de células, tejidos y órganos dañados por factores intrínsecos o extrínsecos." (pág. 11) Prosigue detallando que, el principio de dichos procedimientos radica en las interacciones de los siguien- tes componentes esenciales: células madre, morfógenos y armazones (estructuras, de tejidos). Lo que principalmente se desarrollas son: A) enfoques basados en células, que implican la siembra de células indiferenciadas e inductores bioquímicos adecuados en un diseño estructurado para ser implantados in vivo; y B) enfoques sin células, que proponen que las poblaciones de células madre existentes en el huésped puedan ser extraídas en un armazón bioactivo por quimiotaxis y factores de crecimiento para inducir células migración, proliferación y diferenciación.

Actualmente, la investigación dental aplica protocolos de ingeniería de tejidos y explora el potencial de los productos basados en células como terapias alternativas para reemplazar tejidos como pulpa, dentina y hueso. Los procedimientos de endodoncia 
regenerativa intentan aplicar procedimientos biológicos para sustituir el tejido complejo de dentina-pulpa perdido / dañado para restaurar la función biológica.

La razón biológica para el tratamiento endodóntico es la prevención o el tratamiento de la periodontitis apical a través de la desinfección del espacio del conducto radicular, la conformación del canal y el relleno con un material inerte. Sin embargo, a pesar de los esfuerzos para preservar la mayor cantidad posible de estructura dental, la evidencia sugiere que el tratamiento endodóntico causa la pérdida de una cantidad significativa de dentina, lo que resulta en un diente no vital y debilitado, especialmente cuando los médicos están lidiando con un trauma dental abierto diente del ápice En un estudio retrospectivo, Caplan et al. Encontró que la extracción de pulpa en un diente comprometido puede conducir a la pérdida de dientes en comparación con los dientes con tejidos desarrollados normales. El tratamiento ideal para resolver este problema implicaría mantener la pulpa vital para permitir el desarrollo completo y prevenir la periodontitis apical a través de procedimientos regenerativos.

Bajo estos criterios, el Dr. Jacques Nör declaró que cuando existe la necesidad de tratar endodónticamente un diente con un desarrollo incompleto de la raíz, se pueden aplicar los principios de la medicina regenerativa. Los elementos clave para la ingeniería de la pulpa dental son a) señales moleculares que inducen la diferenciación de las células que constituyen la pulpa dental, b) células que responderán a estas señales yc) andamios que transportarán o atraerán estas células y proporcionarán un entorno para Proliferan, diferencian y desarrollan un tejido con las características y funciones de la pulpa normal. Sin embargo, es necesario estudiar y comprender los principios del desarrollo dental y las diversas vías involucradas en la diferenciación celular para producir un diente de reemplazo funcional o cualquier otro órgano utilizando tecnolo- gías de ingeniería de tejidos. (Retana, 2018, pág. 11)

\section{Reparación de tejidos con tejido dental derivado de Células Madre}

En 2013 Ishida et al. indicaba que:

Las células madre somáticas adultas, tales como las células madre hematopoyéticas, las células madre neurales, las células madre de la piel y las células madre mesenquimales, se someten a una renovación y diferenciación para mantener tejidos sanos y reparar tejidos lesionados. Estudios recientes de células madre / progenitoras derivadas de tejido dental, que pueden diferenciarse en varios linajes de células dentales tales como odontoblastos, células pulpares, ligamento periodontal, cemento y hueso alveolar, han identificado muchas células madre mesenquimales adultas (MSC) -como células. El trasplante de células madre dentales es un concepto prometedor en la terapia regenerativa dental para restaurar la pérdida parcial de la función dental.

Regeneración de tejidos usando células madre/progenitoras derivadas de pulpa dental

La pulpa dental está compuesta de tejido conectivo, vesículas sanguíneas, nervios, fibroblastos y odontoblastos, y se desarrolla de la papila dental después de estar recubierto por tejido dentinario. Las células madre de pulpa dental (DPSC), que tienen propiedades similares a las células madre derivadas de la médula ósea (BMSC), se han aislado de la pulpa dental de terceros molares permanentes humanos. Más recientemente, las células madre de los dientes caducifolios exfoliados humanos (SHED) se identificaron como células MSC derivadas de la médula, ósea, en la pulpa dental de los dientes caducifolios humanos. Las DPSC y SHED poseen propiedades definitivas de células madre, como la autorrenovación y multipotencia. Estas células expresan marcadores MSC incluidos CD73, CD90, CD105, CD146 y STRO-1, y pueden 
diferenciar in vitro en múltiples linajes celulares, incluidos odontoblastos, osteoblastos, adipocitos, condrocitos, miocitos y células similares a las neurales. Las DPSC y las subfracciones de células madre pulpares que pueden generar tejido pulpar, como las células CD31- / CD146- SP y las células CD105+, también pueden ser útiles para la reparación del tejido dental y la regeneración de la pulpa dental. Es muy probable que los factores de crecimiento y las células madre derivadas del tejido dental se apliquen clínicamente para reparar la dentina dañada y el tejido de la pulpa dental en un futuro próximo. (págs. 31-32)

En este punto, se considera valioso nuevamente referir la obra de Guadarrama et al. (2018), ya que, otro dato importante que en este mismo aspecto han aportado ha sido lo relativo a algunos estudios en seres humanos (in vivo). Refieren que:

Recientemente Nakashima y cols. realizaron un estudio piloto, en el cual trasplantaron DPSCs en el espacio radicular de dientes permanentes en pacientes que presentaban pulpitis irreversible, sellando la cavidad con una gelatina absorbible (spongel). El resultado fue que el tratamiento con células pulpares es seguro y eficaz para la regeneración completa pulpar en seres humanos. [...]

Con base en los estudios in vivo mencionados, las células madre pulpares tienen alto potencial en la regeneración de tejidos dentales y maxilofaciales, considerándose como parte de la terapéutica regenerativa de tejidos duros y blandos. (pág. 132)

Los estudios con células madre enfocadas al área dental han reportado que estas células pueden formar estructuras que parecen complejos pulpa-dentina y ligamento periodontal-cemento radicular respectivamente al ser trasplantadas subcutáneamente en ratones inmunocomprometidos, o pueden participar en procesos de reparación periodontal en defectos creados en roedores. [...] Estos y otros datos experimentales, resaltan el potencial de las células madre para lograr la regeneración de tejidos dentarios humanos in

Vivo... (Magallanes, Carmona, \& Álvarez, 2010)

En ese mismo orden de ideas, Romero et al. (2014) fundamentaron su aporte en base a varios estudios para indicar que:

Muchos estudios han demostrado que las DPSCs juegan un papel primordial en la regeneración de los tejidos dentinopulpares. Gronthos y cols. han recombinado DPSCs humanos con hidroxiapatita-fosfato tricálcico (HA-TCP), y los trasplantaron por vía subcutánea en ratones inmunodeficientes. Los tejidos recuperados en este estudio contienen las estructuras típicas de la dentina rodeadas por las células como el odontoblasto, con largos procesos citoplásmicos en la matriz mineralizada. Algunas pulpas dentales, al igual que las estructuras que contienen los vasos sanguíneos, se pueden observar alrededor de la matriz de la dentina. Formaciones similares de dentina puede ser detectada in vivo en SHEDs recombinados con HA-TCP. Por otra parte, las DPSCs son capaces de generar un bosquejo de complejo dentinopulpar y de dentina reparativa sobre una matriz. (pág. 160)

\section{Conclusiones}

En líneas generales, la literatura consultada conlleva a comprender que, por una parte, la ingeniería de tejidos que recientemente se ha centrado en la regeneración de la pulpa dental, tiene como prioridad el avance de estudios con células madre (in vivo e in vitro), en estos casos siendo mayormente usadas las DPSC.

De la misma manera, los avances investigativos sobre estas también allanan las sendas hacia una mayor y mejor comprensión en otras áreas médico-biotecnológicas, por ejemplo, las de terapia celular en enfermedades degenerativas crónicas, en la bioingeniería de tejidos. En sí, con la constante 
evolución de estas especialidades, hacen que cada vez más se vislumbre un asombroso y prometedor panorama en medicina regenerativa, puesto que, en un futuro quizás no muy lejano, es posible que provea a pacientes de una sanación efectiva de sus afecciones y reveladoras mejoras en la calidad de vida.

En plena concordancia con Sloan \& Waddington (2009), aún es posible sostener que, una interesante alternativa a los usuales enfoques en restauración es protagonizado por la regeneración de los tejidos dentales, debido a que un tejido enfermo es reemplazado por un tejido natural, conformando parte integral del diente. De allí pues, las técnicas más recientes, basadas en el reclutamiento de células progenitoras y la estimulación posterior, siguen prometiendo un inmenso potencial para impactar significativamente en el tratamiento de enfermedades dentales y la promoción de la terapia vital de la pulpa.

\section{Bibliografía}

Aguiar, I. (2015). Panorama Atual da Endodontia Regeneradora. Porto: Universidade Fernando Pessoa. doi:10.13140/RG.2.1.3639.3445

Astudillo, E. (2018). Regeneración de la pulpa dental. Una revisión de la literatura. Revista de la Asociación Dental Mexicana, 75(6), 350-357. Recuperado el 04 de 01 de 2020, de https://www.medigraphic.com/pdfs/adm/od-2018/od186i.pdf

Fernández, D. (2019). Nuevas tendencias de andamios en los procedimientos regenerativos endodonticos. Universidad de Carabobo, Unidad de Investigaciones Morfopatológicas (Postgrado). Bárbula: Universidad de Carabobo. Recuperado el 04 de 01 de 2020, de http://mriuc.bc.uc.edu. ve/bitstream/handle/123456789/8357/dfernandez. pdf?sequence $=1$

Gioventù, S., Andriolo, G., Bonino, F., \& Frasca, S. (212). A novel method for banking dental pulp stem cells. Transfus Apher Sci, 47(2), 199-206. doi:10.1016/j.transci.2012.06.005

Guadarrama, O., Guadarrama, L., \& Robles, N. (2018). Aplicaciones odontológicas de las células madre pulpares de dientes temporales y permanentes. Revisión de estudios in vivo. Revista de la Asociación Dental Mexicana, 75(3), 127-134. Recuperado el 04 de 01 de 2020, de https://www. medigraphic.com/pdfs/adm/od-2018/od183c.pdf

Ishida, K., Oshima, M., \& Tsuji, T. (Enero de 2013). Tooth tissue and organ regeneration using stem cells. Inflammation and Regeneration, 33(1), 2937. doi:10.2492/inflammregen.33.029

Magallanes, M., Carmona, B., \& Álvarez, M. (Marzo de 2010). Aislamiento y caracterización parcial de células madre de pulpa dental. Revista Odontológica Mexicana, 14(1), 15-20. Recuperado el 03 de 01 de 2020, de https://www.medigraphic.com/ pdfs/odon/uo-2010/uo101c.pdf

Mendiburu, C., Arce, D., Medina, S., \& Carrillo, J. (Marzo de 2016). Prevalencia de enfermedades pulpares o periapicales. Revista Odontológica Mexicana 2016;20 (1): 22-28, 20(1), 22-28. Recuperado el 02 de 01 de 2020, de https://www.medigraphic.com/pdfs/odon/uo-2016/uo161d.pdf

Munévar, J. (23 de Abril de 2017). Células Troncales: UBSINFO Universidad del Bosque. Recuperado el 02 de 01 de 2020, de UBSINFO Universidad del Bosque: stemuelbosqueblog.wordpress.com/tag/ odontologia-regenerativa/

Retana, C. (Abril de 2018). Dental Pulp Regeneration: Insights from Biological Processes. Odovtos International Journal of Dental Sciences, 20(1), 1016. Recuperado el 03 de 01 de 2020, de https:// www.medigraphic.com/pdfs/odovtos/ijd-2018/ ijd181b.pdf

Romero, S., Córdoba, K., Martínez, C., Gutiérrez, J., Durán, J., \& Munévar, J. (Junio de 2014). Las DPSCs como terapia celular en odontología. Revista Odontológica Mexicana, 18(2), 156-163. Recuperado el 03 de 01 de 2020, de https://www. medigraphic.com/pdfs/odon/uo-2014/uo143b.pdf

Sloan, A., \& Waddington, R. (2009). Dental pulp stem cells Dental pulp stem cells: what, where, how? International Journal of Pediatric Dentistry, 19, 6170. doi:10.1111/j.1365-263X.2008.00964.X

Villa, L., Flores, F., \& Santibáñez, L. (Diciembre de 2017). Células madre de la pulpa dental (DPSC): prospectivas terapéuticas en enfermedades crónico degenerativas. Salud Jalisco, 4(3), 168-177. Recuperado el 04 de 01 de 2020, de https://www. medigraphic.com/pdfs/saljalisco/sj-2017/sj173d. pdf 


\section{CITAR ESTE ARTICULO:}

Mendoza Rodríguez, F., Rosero Mendoza, J., \& Rosero Mendoza, J. (2020). Regeneración de la pulpa dental con DPSC. Una revisión de la literatura. RE-

CIAMUC, 136-147. doi:10.26820/reciamuc/4.(1).enero.2020.136-147

\section{(c) (1) $\odot($ BY NC SA}

RECONOCIMIENTO-NOCOMERCIAL-COMPARTIRIGUAL CC BY-NC-SA

ESTA LICENCIA PERMITE A OTROS ENTREMEZCLAR, AJUSTAR Y CONSTRUIR A PARTIR DE SU OBRA CON FINES NO COMERCIALES, SIEMPRE Y CUANDO LE RECONOZCAN LA AUTORÍA Y SUS NUEVAS CREACIONES ESTÉN BAJO UNA LICENCIA CON LOS MISMOS TÉRMINOS. 